\title{
Computed tomography-based flap brachytherapy for non-melanoma skin cancers of the face
}

\author{
Emile Gogineni, DO, Haocheng Cai, BS, Dawn Carillo, BS, Zaker Rana, MD, Beatrice Bloom, MD, Louis Potters, MD, \\ Hani Gaballa, PhD, Maged Ghaly, MD \\ Department of Radiation Medicine, Northwell Health, Lake Success, NY, USA
}

\begin{abstract}
Purpose: Non-melanoma skin cancers of the face are at high-risk for local recurrence and metastatic spread. While surgical interventions such as Mohs microsurgery are considered the standard of care, this modality has the potential for high rates of toxicity in sensitive areas of the face. Catheter flap high-dose-rate (HDR) brachytherapy has shown promising results, with high rates of local control and acceptable cosmetic outcomes.

Material and methods: Patients with non-melanoma skin cancers (NMSC) located on the face were treated with $40 \mathrm{~Gy}$ in 8 fractions, given twice weekly via catheter flap HDR brachytherapy. Clinical target volume (CTV) included the visible tumor plus a margin of $5 \mathrm{~mm}$ in all directions, with no additional planning target volume (PTV) margin.

Results: Fifty patients with 53 lesions on the face were included, with a median follow-up of 15 months. All were considered high-risk based on NCCN guidelines. Median tumor size and thickness were $18 \mathrm{~mm}$ and $5 \mathrm{~mm}$, respectively. Median PTV volume and $\mathrm{D}_{90}$ were $1.7 \mathrm{cc}$ and $92 \%$, respectively. Estimated rate of local control at twelve months was $92 \%$. Three patients (5\%) experienced acute grade 2 toxicity. Two patients (4\%) continued to suffer from chronic grade 1 skin toxicity at 12 months post-radiotherapy (RT), with an additional two patients (4\%) experiencing chronic grade 2 skin toxicity. Forty-nine lesions (92\%) were found to have a good or excellent cosmetic outcome with complete tumor remission.

Conclusions: CT-based flap applicator brachytherapy is a valid treatment option for patients with NMSC of the face. This modality offers high rates of local control with acceptable cosmetic outcomes and low rates of toxicity.

J Contemp Brachytherapy 2021; 13, 1: 51-58 DOI: https://doi.org/10.5114/jcb.2021.103587
\end{abstract}

Key words: skin cancer, non-melanoma, brachytherapy, flap, face, HDR, radiation, catheter flap.

\section{Purpose}

The incidence of non-melanoma skin cancer (NMSC) in the United States was 5.4 million new cases in 2012 alone [1]. NMSC includes squamous cell carcinoma (SCC), basal cell carcinoma (BCC), and non-epithelial skin cancers. The location of skin cancer is a critical factor for

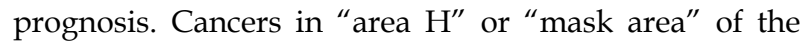
face, including those involving the ear, central face, periorbital, eyebrows, mandible, nose, eyelids, periauricular skin/sulci, and lips, have a higher rate of recurrence due to their close proximity to critical structures and surface irregularity of these locations (Figure 1) [2,3,4]. The National Comprehensive Cancer Network (NCCN) guide-

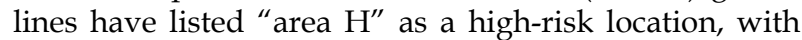
higher potential for tumor relapse and worse prognosis $[5,6]$, with multiple studies providing corresponding evidence $[7,8]$.

Therefore, finding a treatment modality that treats superficial skin cancer, which can limit the rate of recurrence and complications is imperative. Current treatment options for NMSC of the face include local excision, Mohs micrographic surgery (MMS), and radiation therapy (RT) $[9,10,11,12,13,14,15,16]$. Radiation can be delivered via external beam with megavoltage (MV) electrons, kilovoltage and MV photons, or using brachytherapy with lowdose-rate (LDR), high-dose-rate (HDR), and electronic HDR applicators $[17,18,19,20]$.

Mohs micrographic surgery is an appropriate treatment for NMSC in the mask area of face $[3,11,12,13,21]$, especially for deeply infiltrating tumors or when depth is difficult to estimate [22]. RT is also an effective treatment for NMSC, with local control rates exceeding $90 \%$ even when treating tumors, which recurred following initial surgery $[23,24,25,26,27,28]$.

Radiation therapy alone is the preferred treatment for patients, in whom surgery is contraindicated because of age, comorbidities, or poor performance status, and for patients at risk for disfigurement or post-operative scarring due to tumor location. This is in part due to the less invasive nature of RT, which may improve cosmetic out-
Address for correspondence: Maged Ghaly, MD, Department of Radiation Medicine, Northwell Health, 450 Lakeville Road, Lake Success, NY 11042, USA, phone: +1 (516) 321-3122, fax: +1 (516) 470-8445,

e-mail: mghaly@northwell.edu
Received: 07.05 .2020

Accepted: 17.11 .2020

Published: 18.02.2021 


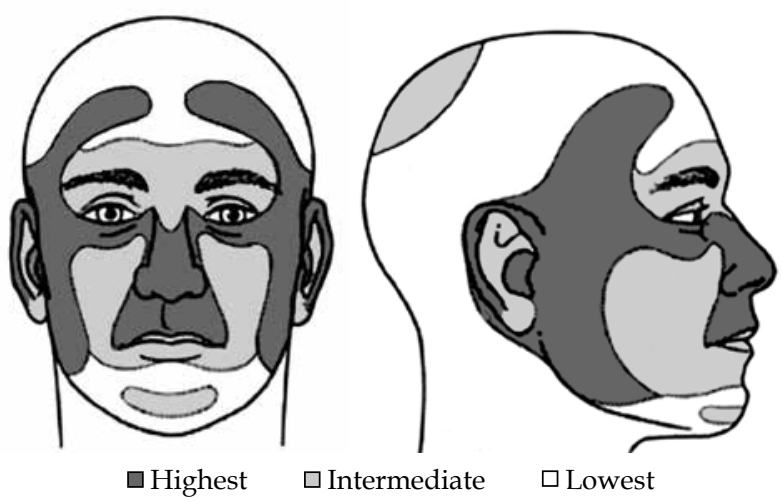

Fig. 1. Mask areas of face. Area M: forehead, scalp, cheek, and neck. Area H: periorbital, eyelids, periauricular, temple, ears, central face, lips, and nose. Photo courtesy of Stein et al. [4]

comes $[29,30]$. A primary limitation of external beam radiation therapy (EBRT) when treating tumors of the face is the difficulty in covering small or irregular fields with dose homogeneity.

Brachytherapy (BT) may be a superior treatment modality due to inherent advantages, such as high-dose concentration in the region of interest with a steep gradient of dose fall off beyond the target, providing the means to spare surrounding normal tissue. Skin high-dose-rate brachytherapy (HDR-BT) utilizing surface applicators has enhanced the ability to treat small fields [31,32].

The catheter flap (Varian Medical Systems, Palo Alto, USA) is a CT-compatible medical-grade silicone flap, with treatment catheters embedded in the material $5 \mathrm{~mm}$ from the surface and $10 \mathrm{~mm}$ apart from each other. Its design creates a gap between the source channels and between the tissue and source. Its flexibility is optimal for irregularly shaped locations. Catheter channels are positioned on the flap's middle axis, each with a diameter of $2 \mathrm{~mm}$. The applicator can be cut to any size and shape in order to suit the region of interest. This has the potential to minimize some of the dose inhomogeneity that can occur when treating uneven surfaces, such as the eyes, ears, and nose, with HDR-BT surface applicator [31,32,33].

The aim of this retrospective review was to assess the efficacy and toxicity profile of a 3D CT-based HDR brachytherapy with the flap applicator in treatment of superficial NMSC of the face.

\section{Material and methods}

\section{Patient characteristics}

From January 2007 to December 2018, patients with superficial NMSC of the face were treated with HDR-BT utilizing the catheter flap. Patients were selected for HDR skin brachytherapy on a case-by-case basis at the discretion of a multidisciplinary dermatology clinic, most commonly based on concerns for inability to tolerate or refusal of surgery. Patients included into this retrospective analysis were those with histopathologically confirmed BCC or SCC, stage T1 disease according to the American Joint Committee on Cancer (AJCC) $8^{\text {th }}$ Edition, and fol- low-up of at least six months. Depth of extension was assessed clinically by the treating physician by palpation. In cases where additional information was available, such as a detailed pathologic assessment from core biopsy that included layers of skin extension, this was also taken into consideration by the treating physician when determining depth of invasion.

\section{Patient set-up, treatment planning, and dose}

Computed tomography simulation was obtained with the patient in a supine position, during which physicians drew the treatment region of interest (ROI) that included the visible tumor plus a $5 \mathrm{~mm}$ margin in all directions to cover microscopic tumor extension [34,35]. CT contrasting wire was placed on the ROI to allow visualization after simulation. The flap applicator extended $10 \mathrm{~mm}$ beyond the ROI margins. To limit radiation doses to organs at risk (OARs), a $5 \mathrm{~mm}$ plastic spacer was placed intranasally in nasal cases, under the eyelid for eyelid lesions, or at the gingivolabial sulcus for skin tumors of the lip. This spacer was placed by the treating physician before CT simulation and each day before treatment delivery.

To ensure contact between the skin and applicator, the flap was secured in a thermoplastic mask (Figure 2). The flap was attached to the mask by glue in order to allow accurate reproducibility. CT simulation with the flap in place was obtained, with $1 \mathrm{~mm}$ thick slices. The clinical target volume (CTV) consisted of the area marked by the CT contrasting wire. The planning target volume (PTV) included the CTV without additional margin. OARs were contoured when the PTV was in close proximity to these structures, such as the eyes, lacrimal glands, and lips. The Varian BrachyVision treatment planning system was used to create a treatment plan with graphical optimization tools to achieve optimum 3D dose distributions. Iridium-192 was utilized as an HDR source, delivered via the GammaMed remote afterloader. Dosimetric goals were at the discretion of the treating physician for $\mathrm{D}_{90}, \mathrm{~V}_{100}$, and conformity in$\operatorname{dex}(\geq 70 \%$ was considered acceptable). $40 \mathrm{~Gy}$ in 8 fractions delivered twice per week was prescribed to cover at least 95\% of the PTV while meeting OARs constraints, which were created from the biologically effective dose (BED) equivalent of those specified by Emami et al. [36]. The dose fractionation scheme was based on our departmental policy, adopted from the original Leipzig protocol [37].

\section{Local response}

Local response was assessed via clinical examination by the treating physician during all follow-up visits.

\section{Toxicity}

Acute toxicity was monitored on a weekly basis while on treatment via the modified Radiation Therapy Oncology Group (RTOG) morbidity criteria. Late skin toxicity was evaluated in all patients and graded by the European Organization for Research and Treatment of Cancer (EORTC) skin late radiation morbidity scoring every six months following treatment completion. Cosmetic outcomes were graded based on Harris scale scoring system [38]. 

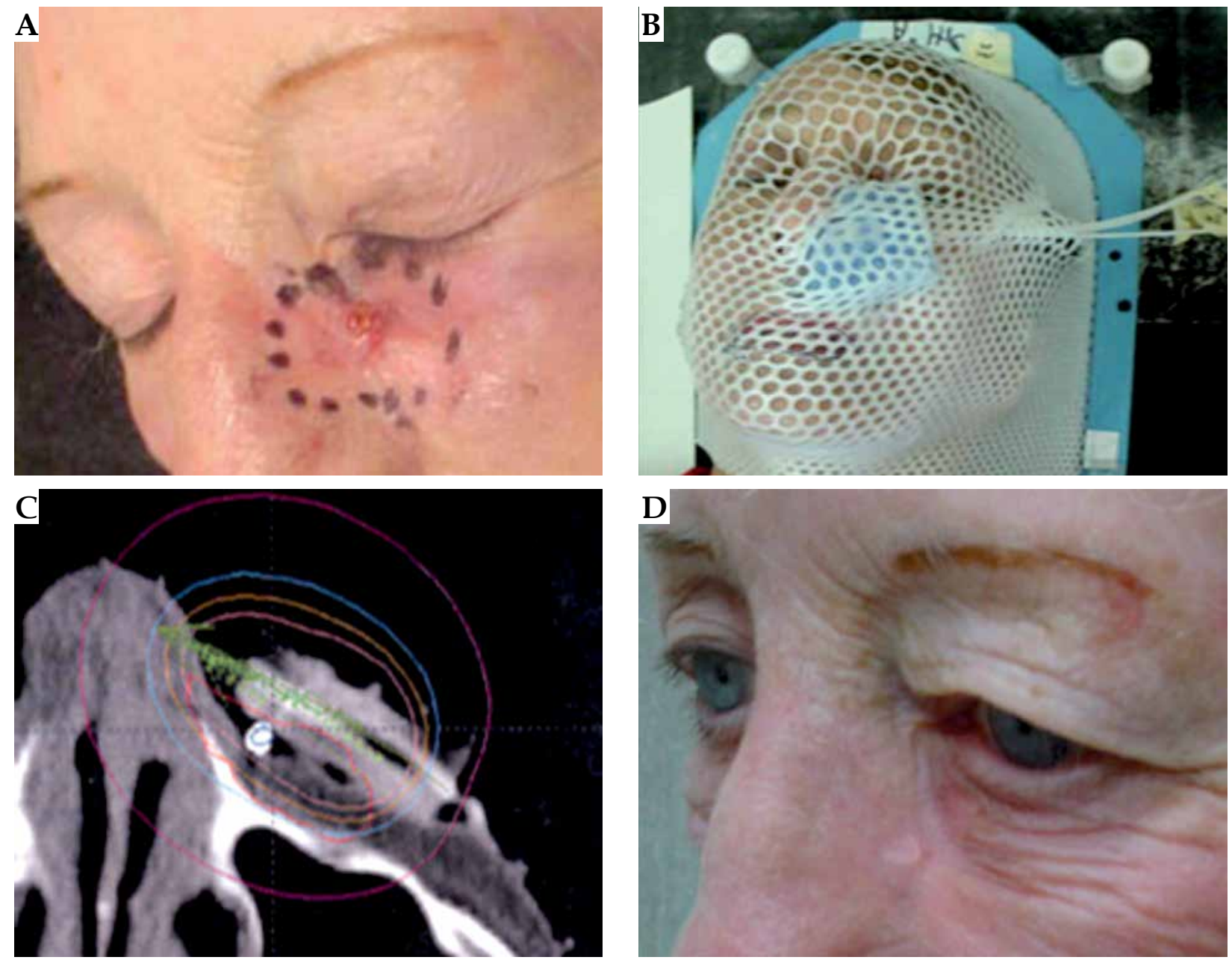

Fig. 2. An example of an 82-year-old female patient, who presented with a lesion of the medial inferior eyelid (A). Flap applicator was placed, and thermoplastic mask was created to secure its position (B). Simulation CT was obtained (C). 40 Gy in 8 twice weekly fractions was delivered using HDR-brachytherapy. During the final week of treatment, she developed grade 1 conjunctivitis, which was treated with a two-day course of antibiotic/steroid eye suspension. On initial follow-up one-month post-treatment, her conjunctivitis had resolved, and the lesion had diminished in size. By follow-up at seven months, her lesion had completely resolved, with minimal hypopigmentation or scarring (D)

\section{Statistical considerations}

Continuous variables were expressed using sample medians, while categorical variables were expressed as percentages. Kaplan-Meier method was used to estimate local control. SPSS (IBM, Armonk, NY, USA) version 21 was used for all statistical analyses.

\section{Results}

Patient characteristics are presented in Table 1. Fifty patients with 53 lesions were included for analysis with a median follow-up of 15 months (range, 6-27 months). Forty-eight $(91 \%)$ lesions were primary tumors and $5(9 \%)$ were recurrences, which included 3 post-operative recurrences and 2 recurrences after photodynamic therapy. All were considered high-risk based on the NCCN guidelines, where they were classified either as located in

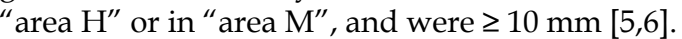

All patients completed treatment without interruption to total dose of 40 Gy in 8 fractions given twice week- ly (BED of $60 \mathrm{~Gy}$, assuming $\alpha / \beta$ of $10 \mathrm{~Gy}$ ). Median PTV volume, $\mathrm{D}_{90}$, and $\mathrm{V}_{100}$ were $1.7 \mathrm{cc}(95 \%$ confidence interval [CI]: $0.9-2.3), 92 \%$ (95\% CI: 82-99), and 85\% (95\% CI: 80-92), respectively.

All acute skin toxicities that occurred were observed after the $5^{\text {th }}$ fraction. Thirty-two patients $(60 \%)$ developed grade 1 toxicity (skin erythema). Nineteen patients (35\%) experienced grade 2 toxicity (bright erythema, patchy moist desquamation, or moderate edema). Three patients (5\%) suffered from grade 3 toxicity (acute dermatitis with patches and moist desquamation). All eight patients with eyelid or peri-orbital lesions developed ipsilateral grade 1 acute conjunctivitis by the last week of their treatment course, which responded to an antibiotic/steroid combination eye suspension, given for two days after the treatment completion.

Five patients (10\%) experienced chronic grade 1 skin toxicity at 6 months post-RT, which included slight atrophy or pigmentation change. Two patients $(4 \%)$ continued to suffer from chronic grade 1 hypopigmentation and 
Table 1. Patient characteristics ( $n=50$ patients, 53 lesions)

\begin{tabular}{|c|c|}
\hline & $n(\%)$ \\
\hline Age (years), median (range) & $80(73-101)$ \\
\hline \multicolumn{2}{|l|}{ Gender } \\
\hline Male & $23(46)$ \\
\hline Female & $27(54)$ \\
\hline \multicolumn{2}{|l|}{ Histology } \\
\hline Basal cell carcinoma & $35(66)$ \\
\hline Squamous cell carcinoma & $18(34)$ \\
\hline Tumor size (mm), median (range) & $18(5-20)$ \\
\hline Tumor thickness (mm), median (range) & $5(3-7)$ \\
\hline \multicolumn{2}{|l|}{ Location } \\
\hline Area $\mathrm{H}$ & $40(75)$ \\
\hline Nose & $17(32)$ \\
\hline Temple & $8(15)$ \\
\hline Eyelid & $6(11)$ \\
\hline Ear & $4(8)$ \\
\hline Lip & $3(6)$ \\
\hline Peri-orbital & $2(4)$ \\
\hline Area $M$ & $13(25)$ \\
\hline Scalp & $5(9)$ \\
\hline Forehead & $4(8)$ \\
\hline Cheek & $2(4)$ \\
\hline Neck & $2(4)$ \\
\hline
\end{tabular}

two patients (4\%) continued to experience grade 2 telangiectasias at 12 months post-RT. There were no chronic grade $\geq 3$ toxicities. No patient required hospitalization secondary to treatment-related toxicity.

Estimated local control at one year was $92 \%$ using the Kaplan-Meier method. There were four local recurrences at final follow-up, including two nasal SCC lesions, one eyelid BCC lesion, and one lip BCC lesion. Forty-nine lesions $(92 \%)$ were found to have a good or excellent cosmetic outcome with complete tumor remission.

\section{Discussion}

Patients with NMSC in areas, which are cosmetically sensitive, are not ideal candidates for resection, particularly in cases where an extensive surgical defect may result or if a complex reconstruction is required. Preservation of tissue may be more achievable by radiotherapy for these patients, leading to improved cosmetic outcomes without increasing the risk of local failure [39,40]. A large-scale systematic review and pooled analysis found no statistically significant difference between local recurrence rates of SCC of the skin after Mohs micrographic surgery, external beam radiotherapy, and brachytherapy [41].

Thus far, there has only been one randomized controlled trial for patients with BCC of the face comparing surgery versus radiation. Three RT techniques were utilized, including interstitial BT (55\% of patients), superficial contact therapy (33\% of patients), and conventionally fractionated EBRT (12\% of patients). Rate of failure at four years was higher with RT than surgery $(7.5 \%$ vs. $0.7 \%$ ). Cosmetic results were also found to be significantly better after surgery than after RT. However, no outcome analysis was conducted comparing treatment sites or RT techniques [42,43].

Despite technological advancements, studies assessing outcomes of NMSC treated with HDR-BT have been sparse. Furthermore, hypofractionation has shown excellent rates of local control, toxicity, and cosmetic results in the treatment of NMSC [44].

We found rates of local control (92\%) comparable to those reported in the literature. Other retrospective studies using HDR-BT with surface molds for NMSC reported local control rates between $87 \%$ and $100 \%$ $[45,46,47,48,49,50]$.

In our study, 49 patients (92\%) had good/excellent cosmetic outcomes with complete tumor remission. Three patients $(5 \%)$ experienced grade 3 acute dermatitis with patches and moist desquamation. Two patients developed mild skin telangiectasia and 2 developed skin hypopigmentation one-year post-radiation. Similar studies using HDR-BT or electronic BT reported equivalent results, with high rates of acceptable cosmetic outcomes in follow-up [31,51,52,53,54,55,56,57].

There are several established differences between BCC and SCC, such as their natural history, patterns of spread, and recurrence rates $[58,59,60,61,62,63]$. Therefore, management strategies for SCC and BCC vary in terms of imaging and local and systemic therapy $[5,6]$.

One factor to consider when assessing an ideal radiation fractionation is a tumor's $\alpha / \beta$ ratio, which is a measure of its radiosensitivity, with higher ratios suggesting less susceptibility to the sparing effect of fractionation. While the $\alpha / \beta$ ratio of NMSC is generally accepted as being higher than that of melanoma, there has been no established consensus on comparison of the $\alpha / \beta$ ratios of BCC and SCC, with most studies combining the two together $[64,65]$.

This leads to the question of whether radiation fractionation should differ between BCC and SCC. While indications for post-operative radiation and treatment of regional lymphatic stations change depending on histology, the NCCN guidelines list identical doses and fractionation schema for BCC and SCC when treating definitively with radiation $[5,6]$. This similarity is also reflected in the 2020 American Society for Radiation Oncology (ASTRO) guidelines and the 2019 American Brachytherapy Society (ABS) consensus statement for skin brachytherapy, which do not separate by histology $[66,67]$. The 2020 ABS consensus statement for skin brachytherapy suggests that there may be differences in radiosensitivity between the two entities and that different equivalent doses may be targeted for each. However, the data supporting this con- 


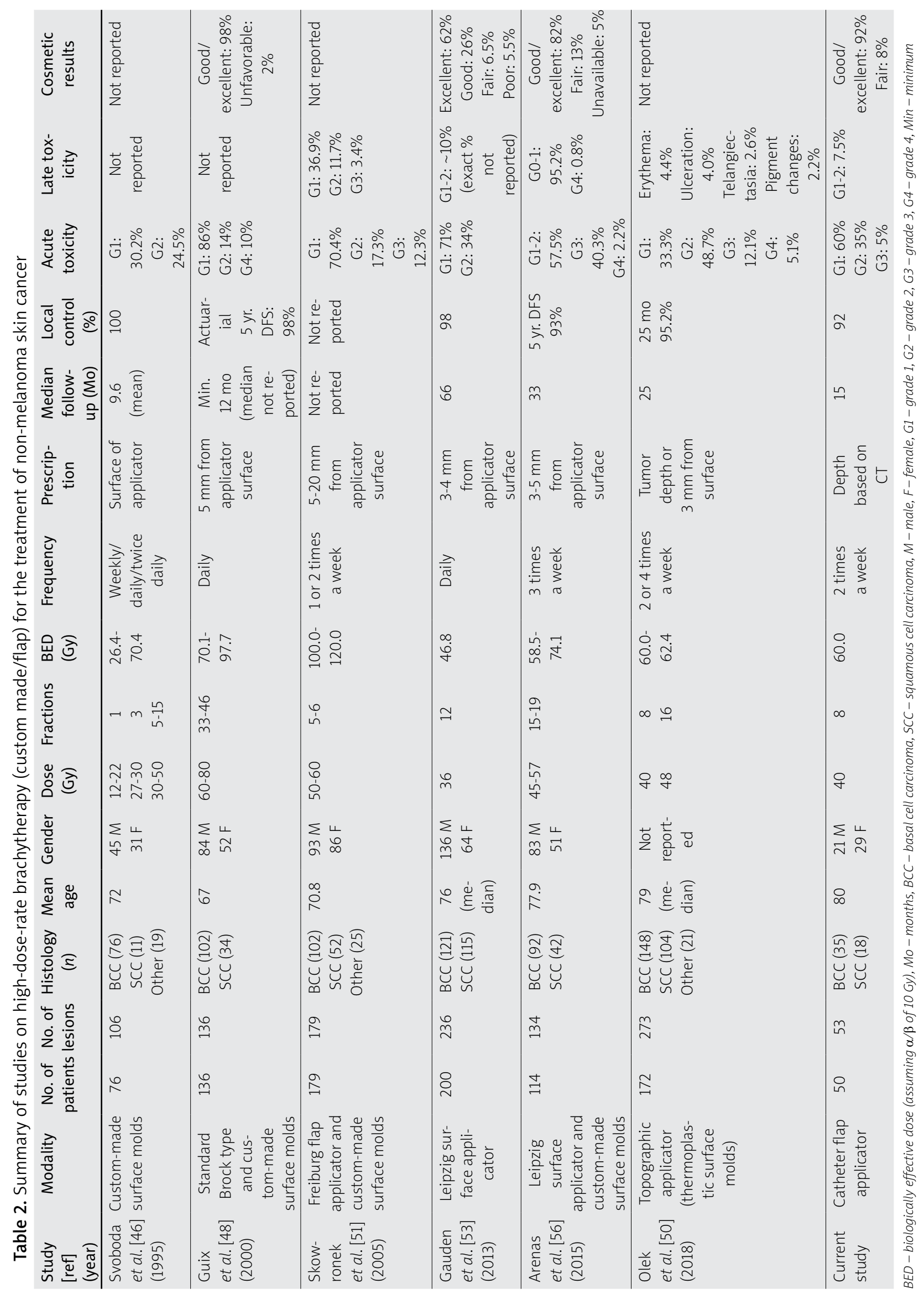


cept remains limited at this time, and many practitioners do not change their dosing strategy based on histology [68]. There are others who modify their radiation volumes based on histology, such as the GEC-ESTRO recommendations published by Guinot et al. in 2018, which used different CTV margins for BCC and SCC [69]. The majority of studies treating NMSC with HDR brachytherapy did not change their prescription dose or margins based on histology $[24,46,47,53,62]$. It is for this reason that we treated BCC and SCC similarly.

HDR-BT was well tolerated in our cohort, with low rates of severe acute toxicity and no chronic grade $\geq 2$ toxicities. There have been some studies suggesting that a large dose per fraction used during HDR-BT have high rates of late toxicity $[48,51,54,70]$. The data presented herein suggests that 40 Gy delivered in 8 fractions given twice per week can result in acceptable late toxicity, with mild skin telangiectasia and hypopigmentation in only 4 patients $(8 \%)$. The majority of available literature reports high rates of local control and acceptable acute and chronic toxicity with the use of HDR-BT (Table 2).

A limitation of this study was the short follow-up, with a median of 15 months. It remains to be observed if continued follow-up would reveal higher rates of recurrence and/ or late toxicity. Results from Gauden et al., with a median follow-up of 66 months, showed that rates of chronic toxicity stabilized with longer follow-up, suggesting that the majority of toxicity may occur in the first one to two years after treatment [53].

\section{Conclusions}

Computed tomography-based flap applicator brachytherapy is a valid treatment option for patients with superficial non-melanoma skin cancer of the face when surgery is not feasible, with high rates of local control and low rates of toxicity. Large-scale prospective randomized controlled trials and longer follow-up are needed to assess the ultimate efficacy and safety of HDR-BT in comparison with other modalities.

\section{Disclosure}

The authors report no conflict of interest.

\section{References}

1. Rogers HW, Weinstock MA, Feldman SR, Coldiron BM. Incidence estimate of nonmelanoma skin cancer (keratinocyte carcinomas) in the U.S. population, 2012. JAMA Dermatol 2015; 151: 1081-1086.

2. Silverman MK, Kopf AW, Grin CM et al. Recurrence rates of treated basal cell carcinomas: Part 2: curettage-electrodesiccation. J Dermatol Surg Oncol 1991; 17: 720-726.

3. Chu MB, Slutsky JB, Dhandha MM et al. Evaluation of the definitions of "high-risk" cutaneous squamous cell carcinoma using the American Joint Committee on Cancer Staging Criteria and National Comprehensive Cancer Network Guidelines. J Skin Cancer 2014; 2014: 154340.

4. Stein JM, Hrabovsky S, Schuller DE, Siegle RJ. Mohs micrographic surgery and the otolaryngologist. Am J Otolaryngol 2004; 25: 385-393.

5. National Comprehensive Cancer Network. Basal cell skin cancer (version 1.2020). Available at: www.nccn.org/prof- ressionals/physicians_gls/pdf/nmsc.pdf (accessed May 1, 2020).

6. National Comprehensive Cancer Network. Squamous cell skin cancer (version 1.2020). Available at: www.nccn.org/ profressionals/physicians_gls/pdf/squamous.pdf (accessed May 1, 2020).

7. Rowe DE, Carroll RJ, Day CL. Prognostic factors for local recurrence, metastasis, and survival rates in squamous cell carcinoma of the skin, ear, and lip: Implications for treatment modality selection. J Am Acad Dermatol 1992; 26: 976-990.

8. Cheng J, Yan S. Prognostic variables in high-risk cutaneous squamous cell carcinoma: a review. J Cutan Pathol 2016; 43: 994-1004.

9. Swanson NA. Mohs surgery: technique, indications, applications, and the future. Arch Dermatol 1983; 119: 761-773.

10. Rowe DE, Carroll RJ, Day CL. Long-term recurrence rates in previously untreated (primary) basal cell caricnoma: implications for patient follow-up. J Dermatol Surg Oncol 1989; 15: 315-328.

11. Rowe DE, Carroll RJ, Day CL. Mohs surgery is the treatment of choice for recurrent (previously treated) basal cell carcinoma. J Dermatol Surg Oncol 1989; 15: 424-431.

12. Mosterd K, Krekels GA, Nieman FH et al. Surgical excision versus Mohs' micrographic surgery for primary and recurrent basal-cell carcinoma of the face: a prospective randomised controlled trial with 5-years' follow-up. Lancet Oncol 2008; 9: 1149-1156.

13. van Loo E, Mosterd K, Krekels GA et al. Surgical excision versus Mohs' micrographic surgery for basal cell carcinoma of the face: A randomised clinical trial with 10 year follow-up. Eur J Cancer 2014; 50: 3011-3020.

14. Bath-Hextall F, Bong J, Perkins W, Williams H. Interventions for basal cell carcinoma of the skin: systematic review. BMJ 2004; 329: 705.

15. Griffiths RW, Feeley K, Suvarna SK. Audit of clinical and histological prognostic factors in primary invasive squamous cell carcinoma of the skin: assessment in a minimum 5 year follow-up study after conventional excisional surgery. $\mathrm{Br}$ J Plast Surg 2002; 55: 287-292.

16. Smeets NW, Krekels GA, Ostertag JU et al. Surgical excision vs Mohs' micrographic surgery for basal-cell carcinoma of the face: randomised controlled trial. Lancet 2004; 364: 1766-1772.

17. Bhatnagar A. Nonmelanoma skin cancer treated with electronic brachytherapy: Results at 1 year. Brachytherapy 2013; 12: $134-140$

18. Skowronek J. Brachytherapy in the treatment of skin cancer: an overview. Postepy Dermatol Alergol 2015; 32: 362-367.

19. Goldschmidt H. Dermatologic radiotherapy: the risk-benefit ratio. JAMA Dermatology 1986; 122: 1385-1388.

20. Vavassori A, Riva G, Durante S et al. Mould-based surface high-dose-rate brachytherapy for eyelid carcinoma. J Contemp Brachytherapy 2019; 11: 443-448.

21. Connolly SM, Baker DR, Coldiron BM et al. AAD/ACMS/ ASDSA/ASMS 2012 appropriate use criteria for Mohs micrographic surgery: A report of the American Academy of Dermatology, American College of Mohs Surgery, American Society for Dermatologic Surgery Association, and the American Society for Mohs Surgery. Dermatol Surg 2012; 38: 1582-1603.

22. Asgari MM, Olson JM, Alam M. Needs assessment for Mohs micrographic surgery. Dermatol Clin 2012; 30: 167-175.

23. Huynh NT, Veness MJ. Basal cell carcinoma of the lip treated with radiotherapy. Australas J Dermatol 2002; 43: 15-19.

24. Mendenhall WM, Amdur RJ, Hinerman RW et al. Radiotherapy for cutaneous squamous and basal cell carcinomas of the head and neck. Laryngoscope 2009; 119: 1994-1999.

25. Kropp L, Balamucki CJ, Morris CG et al. Mohs resection and postoperative radiotherapy for head and neck cancers with 
incidental perineural invasion. Am J Otolaryngol 2013; 34: 373-377.

26. Locke J, Karimpour S, Young G et al. Radiotherapy for epithelial skin cancer. Int J Radiat Oncol Biol Phys 2001; 51: 748755.

27. Schulte KW, Lippold A, Auras C et al. Soft x-ray therapy for cutaneous basal cell and squamous cell carcinomas. I Am Acad Dermatol 2005; 53: 993-1001.

28. Kwan W, Wilson D, Moravan V. Radiotherapy for locally advanced basal cell and squamous cell carcinomas of the skin. Int J Radiat Oncol Biol Phys 2004; 60: 406-411.

29. Kauvar ANB, Cronin T, Roenigk R et al. Consensus for nonmelanoma skin cancer treatment. Dermatol Surg 2015; 41: 550-571.

30. American Academy of Dermatology. Position statement on electronic surface brachytherapy for basal cell carcinoma (BCC) and squamous cell carcinomas (SCC).

31. Frakulli R, Galuppi A, Cammelli S et al. Brachytherapy in non melanoma skin cancer of eyelid: A systematic review. J Contemp Brachytherapy 2015; 7: 497-502.

32. Ouhib Z, Kasper M, Calatayud JP et al. Aspects of dosimetry and clinical practice of skin brachytherapy: The American Brachytherapy Society working group report. Brachytherapy 2015; 14: 840-858

33. Parsai E, Horne S, Shvydka D, Carroll TM. Dosimetric analysis of irregular surfaces treated with the Leipzig and Valencia HDR skin applicators. Int J Radiat Oncol Biol Phys 2013; 87: S693.

34. Choo R, Woo T, Assaad D et al. What is the microscopic tumor extent beyond clinically delineated gross tumor boundary in nonmelanoma skin cancers? Int J Radiat Oncol Biol Phys 2005; 62: 1096-1099.

35. Thomas DJ, King AR, Peat BG. Excision margins for nonmelanotic skin cancer. Plast Reconstr Surg 2003; 112: 57-63.

36. Emami B, Lyman J, Brown A et al. Tolerance of normal tissue to therapeutic irradiation. Int J Radiat Oncol Biol Phys 1991; 21: 109-122.

37. Köhler-Brock A, Prager W, Pohlmann S, Kunze S. The indications for and results of HDR afterloading therapy in diseases of the skin and mucosa with standardized surface applicators (the Leipzig applicator). Strahlenther Onkol 1999; 175: 170-174

38. Harris JR, Levene MB, Svensson G, Hellman S. Analysis of cosmetic results following primary radiation therapy for stages I and II carcinoma of the breast. Int J Radiat Oncol Biol Phys 1979; 5: 257-261.

39. Lee CT, Lehrer EJ, Aphale A et al. Surgical excision, Mohs micrographic surgery, external-beam radiotherapy, or brachytherapy for indolent skin cancer: An international meta-analysis of 58 studies with 21,000 patients. Cancer 2019; 125: 3582-3594.

40. Patel R, Strimling R, Doggett S et al. Comparison of electronic brachytherapy and Mohs micrographic surgery for the treatment of early-stage non-melanoma skin cancer: a matched pair cohort study. J Contemp Brachytherapy 2017; 9: 338-344.

41. Lansbury L, Bath-Hextall F, Perkins W et al. Interventions for non-metastatic squamous cell carcinoma of the skin: Systematic review and pooled analysis of observational studies. BMJ 2013; 347: f6153.

42. Petit JY, Avril MF, Margulis A et al. Evaluation of cosmetic results of a randomized trial comparing surgery and radiotherapy in the treatment of basal cell carcinoma of the face. Plast Reconstr Surg 2000; 105: 2544-2551.

43. Avril MF, Auperin A, Margulis A et al. Basal cell carcinoma of the face: surgery or radiotherapy? Results of a randomized study. Br J Cancer 1997; 76: 100-106.

44. Delishaj D, Rembielak A, Manfredi B et al. Non-melanoma skin cancer treated with high-dose-rate brachytherapy: A review of literature. J Contemp Brachytherapy 2016; 8: 533-540.
45. Hwang IM, Lin SY, Lin LC et al. Alternative effective modality of Leipzig applicator with an electron beam for the treatment of superficial malignancies. Nucl Instruments Methods Phys Res Sect A Accel Spectrometers Detect Assoc Equip 2003; 508: 460-466.

46. Svoboda VH, Kovarik J, Morris F. High dose-rate microselectron molds in the treatment of skin tumors. Int J Radiat Oncol Biol Phys 1995; 31: 967-972.

47. Kohler-Brock A, Prager W, Pohlmann S, Kunze S. The indications for and results of HDR afterloading therapy in diseases of the skin and mucosa with standardized surface applicators (the Leipzig applicator). Strahlenther Onkol 1999; 175: 170-174.

48. Guix B, Finestres F, Tello J et al. Treatment of skin carcinomas of the face by high-dose-rate brachytherapy and custom-made surface molds. Int J Radiat Oncol Biol Phys 2000; 47: 95-102.

49. Kalaghchi B, Esmati E, Ghalehtaki R et al. High-dose-rate brachytherapy in treatment of non-melanoma skin cancer of head and neck region: preliminary results of a prospective single institution study. J Contemp Brachytherapy 2018; 10: 115-122.

50. Olek D, El-Ghamry MN, Deb N et al. Custom mold applicator high-dose-rate brachytherapy for nonmelanoma skin cancer - an analysis of 273 lesions. Brachytherapy 2018; 17: 601-608.

51. Skowronek J, Chicheł A, Piotrowski T. HDR brachytherapy of skin cancer - The Wielkopolski Cancer Centre's experience. Wspolcz Onkol 2005; 9: 347-354.

52. Ghaly M, Zinkin H, Dannenberg M et al. HDR brachytherapy with standardized surface applicators in the treatment of superficial malignant skin lesions. Int J Radiat Oncol 2008; 72: S505-506

53. Gauden R, Pracy M, Avery AM et al. HDR brachytherapy for superficial non-melanoma skin cancers. J Med Imaging Radiat Oncol 2013; 57: 212-217.

54. Kanikowski M. HDR brachytherapy of skin cancer in material of Greater Poland Cancer Center. J Contemp Brachytherapy 2009; 1: 197.

55. Tormo A, Celada F, Rodriguez $\mathrm{S}$ et al. Non-melanoma skin cancer treated with HDR Valencia applicator: clinical outcomes. J Contemp Brachytherapy 2014; 6: 167-172.

56. Arenas M, Arguís M, Díez-Presa L et al. Hypofractionated high-dose-rate plesiotherapy in nonmelanoma skin cancer treatment. Brachytherapy 2015; 14: 859-865.

57. Delishaj D, Laliscia C, Manfredi B et al. Non-melanoma skin cancer treated with high-dose-rate brachytherapy and Valencia applicator in elderly patients: a retrospective case series. J Contemp Brachytherapy 2015; 7: 437-444.

58. Khan L, Breen D, Zhang L et al. Predictors of recurrence after radiotherapy for non-melanoma skin cancer. Curr Oncol 2014; 21: e326-329.

59. Fahradyan A, Howell An, Wolfswinkel E et al. Updates on the management of non-melanoma skin cancer (NMSC). Healthcare (Besel) 2017; 5: 82.

60. Garcovich S, Colloca G, Sollena P et al. Skin cancer epidemics in the elderly as an emerging issue in geriatric oncology. Aging Dis 2017; 8: 643-661.

61. Veness MJ, Goedjen B, Jambusaria-Palajani A. Perioperative management of high risk primary cutaneous SCC: Role of radiologic imaging, elective lymph node dissection, sentinel lymph node biopsy, and adjuvant radiotherapy. Curr Dermatol Rep 2013; 2: 77-83.

62. Ducassou A, David I, Filleron T et al. Retrospective analysis of local control and cosmetic outcome of 147 periorificial carcinomas of the face treated with low-dose rate interstitial brachytherapy. Int J Radiat Oncol Biol Phys 2011; 81: 726-731. 
63. Choo R, Woo T, Assad D et al. What is the microscopic tumor extent beyond clinically delineated gross tumor boundary in nonmelanoma skin cancers? Int J Radiat Oncol Biol Phys 2005; 62: 1096-1099.

64. Trott KR, Maciejewski B, Preuss-Bayer G, Skolyszewski J. Dose-response curve and split-dose recovery in human skin cancer. Radiother Oncol 1984; 2: 123-129.

65. van Leeuwen CM, Oei AL, Crezee J et al. The alfa and beta of tumors: a review of parameters of the linear-quadratic model, derived from clinical radiotherapy studies. Radiat Oncol 2018; 13: 96

66. Likhacheva A, Awan M, Barker C et al. Definitive and postoperative radiation therapy for basal and squamous cell cancers of the skin: executive summary of an American Society for Radiation Oncology Clinical Practice Guideline. Pract Radiat Oncol 2020; 10: 8-20.

67. Tom M, Hepel J, Patel R et al. The American Brachytherapy Society consensus statement for electronic brachytherapy. Brachytherapy 2019; 18: 292-298.

68. Shah C, Ouhib Z, Kamrava Met al. The American Brachytherapy Society consensus statement for skin brachytherapy. Brachytherapy 2020; 19: 415-426.

69. Guinot J, Rembielak A, Perez-Calatayud J et al. GEC-ESTRO ACROP recommendations in skin brachytherapy. Radiother Oncol 2018; 126: 377-385.

70. Daly NJ, De Lafontan B, Combes PF. Results of the treatment of 165 lid carcinomas by iridium wire implant. Int J Radiat Oncol Biol Phys 1984; 10: 455-459. 